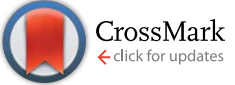

Cite this: RSC Adv., 2017, 7, 10192

\title{
Rapid bactericidal activity of an amphiphilic polyacrylate terpolymer system comprised of same-centered comonomers with 2-carbon and 6- carbon spacer arms and an uncharged repeat unit $\dagger$
}

\author{
Kamia Punia, $\dot{+}^{\mathrm{a}}$ Ashish Punia, $\dot{\dagger}^{\mathrm{a}}$ Kaushiki Chatterjee, ${ }^{\mathrm{b}}$ Sumit Mukherjee, ${ }^{\mathrm{c}} \mathrm{Jimmie}$ Fata, ${ }^{\mathrm{b}}$ \\ Probal Banerjee, ${ }^{c}$ Krishnaswami Raja ${ }^{a}$ and Nan-Loh Yang ${ }^{* a}$
}

\begin{abstract}
The global health threat of antimicrobial resistance has created a pressing need to develop practical alternatives to conventional antibiotic agents. Peptide mimetic synthetic amphiphilic polymers are known to non-specifically disrupt the bacterial cell surface thus leading to highly hindered bacterial resistance development. We investigated the antibacterial activities of a terpolymer macromolecular architecture with a combination of 6carbon and 2-carbon spacer arms (distance from polymer backbone to pendent cationic center) interspersed with counits with hydrophobic side groups. A random copolymer with a combination of 6 -carbon spacer arm repeat units (60 mol\%) and 2-carbon spacer arm (40 mol\%) units is moderately active against bacteria and shows very low hemolytic activity. Incorporation of comonomer units with alkyl side groups, by replacing different levels of 2-carbon spacer arm counit, led to substantial increments in antibacterial activities without detrimental effects on hemolytic activities leading to highly selective (bacteria over red blood cells) antibacterial activity. Time-kill studies revealed rapid bactericidal activity of the terpolymer against both Staphylococcus aureus and Escherichia coli with 100\% killing efficiency achieved within $1 \mathrm{~h}$ of polymer treatment, corresponding to a 5-log reduction of bacterial colony forming units. These results indicate the high potential of this amphiphilic terpolymer architecture in the development of alternatives to antibiotics.
\end{abstract}

Received 3rd January 2017

Accepted 1st February 2017

DOI: $10.1039 / \mathrm{c} 7 \mathrm{ra00047b}$

rsc.li/rsc-advances natural antimicrobial peptides (AMPs) can provide the urgently needed solution to the superbug threat. ${ }^{7-9}$ The non-specific mode of antibacterial action (membrane rupture through electrostatic and lipophilic interactions) of AMPs and their synthetic polymeric mimics hinders the development of bacterial resistance. ${ }^{10,11}$ High activity of synthetic amphiphilic polymers against antibiotic resistant bacteria and the inability of bacteria to develop resistance against synthetic amphiphilic polymers, in contrast to conventional antibiotic, has been documented. ${ }^{12}$

Understanding the role that polymeric design features plays in their antibacterial activities and toxicities towards mammalian cells is critical for their successful wide scale application as therapeutic agents. For biomedical applications, selective activity of amphiphilic polymers against bacteria over mammalian cells is highly desired. However, the macromolecular design features affecting the bacterial cell versus mammalian cell toxicity have not been well understood, and a number of studies in recent years have focused on the development of structure-activity relationships for synthetic amphiphilic polymers. ${ }^{13-44}$

We have recently shown that control of spatial cationic charge density through variation in spacer arm (distance from polymer backbone to cationic center) design can lead to highly selective (bacteria over red blood cells) antibacterial activity. ${ }^{41}$ The homopolymer of 6-carbon spacer arm is highly antibacterial

\$ These authors contributed equally. 
and hemolytic, whereas the homopolymer of 2-carbon spacer arm monomer has low activity against Escherichia coli (E. coli) but displayed non-hemolytic activity. ${ }^{41}$ Interestingly, copolymerization of just a small mol\% of 2-carbon spacer arm monomer with 6-carbon spacer arm monomer led to three orders of magnitude reduction in hemolytic activity without significant deterioration of antibacterial activities. ${ }^{41}$ On the other hand, it has been shown in earlier reports that "separate center" copolymer architecture with cationic and hydrophobic groups on separate repeat units shows higher antibacterial and hemolytic activity in comparison with "same center" homopolymer with cationic and hydrophobic groups on same repeat unit. ${ }^{44}$

Here we report a new terpolymer architecture with a combination of "same center" 6-carbon and 2-carbon spacer arm design with "separate center" architecture by interspersing cationic repeat units with hydrophobic repeat units. The mol\% content of 6-carbon spacer arm repeat units was kept approximately constant while the effects of variation in mol\% of 2-carbon spacer arm with respect to alkyl acrylates and the length of alkyl side group were investigated on the antibacterial and hemolytic activities of these terpolymers. Our investigations found that the combination of spacer arm and separate center design can have a synergistic effect leading to increment in antibacterial activity and the optimization of amphiphilic balance and lipophilicity can result in concomitant lower hemolytic activity. Moreover, the resultant copolymer displayed rapid bactericidal activity against both Gram negative and Gram positive bacteria underlining the anti-infective potential of these amphiphilic macromolecules.

\section{Experimental}

\section{Materials and instrumentation}

6-Amino-1-hexanol, 2-(methylamino)ethanol, 2,2'-azobis(2methylpropionitrile) (AIBN), methyl 3-mercaptopropionate
(MMP), $N, N$-diisopropylethylamine, acetonitrile (anhydrous), hexane, diethyl ether, and methanol were purchased from Sigma-Aldrich and were used without further purification. Acryloyl chloride was purchased from Sigma-Aldrich and was purified by distillation prior to use. Ethyl acrylate, methyl acrylate, and butyl acrylate were obtained from Sigma-Aldrich and were treated with inhibitor remover prior to use. Trifluoroacetic acid and di-tert-butyl dicarbonate ( $t$-Boc) were purchased from Alfa Aesar and were used without further purification.

${ }^{1} \mathrm{H}$ NMR spectra were obtained on a Varian Unity NMR spectrometer $(600 \mathrm{MHz})$ using $\mathrm{CDCl}_{3}$ or $\mathrm{D}_{2} \mathrm{O}$ as solvents. Molecular weights of polymers were estimated against linear polystyrene standards via gel permeation chromatography using an EcoSec HLC-83220 gel permeation chromatography instrument (RI detector, TSKgel SuperHZ-N (3 $\mu \mathrm{m} 4.6 \mathrm{~mm}$ ID) and TSKgel SuperHZ-M ( $3 \mu \mathrm{m} 4.6 \mathrm{~mm}$ ID) columns). Tetrahydrofuran was used a solvent for GPC at a flow rate of $0.35 \mathrm{~mL} \min ^{-1}$.

\section{Synthesis of monomers and polymers}

$\mathrm{N}$-Boc protected amine functionalized acrylate monomers (M6 and M2, Scheme 1) were synthesized as described in literature. ${ }^{\mathbf{4 1}}$ Copolymers were synthesized via free radical polymerization and $N$-Boc protecting groups were subsequently cleaved by treatment with excess trifluoroacetic acid. ${ }^{\mathbf{4 0 - 4 4}} \mathrm{A}$ representative synthesis procedure is as follows. $1.30 \mathrm{~g}$ ( $4.8 \mathrm{mmol})$ of monomer M6, $0.51 \mathrm{~g}$ ( $2.24 \mathrm{mmol})$ of monomer M2, and $0.096 \mathrm{~g}$ (0.96 $\mathrm{mmol}$ ) of ethyl acrylate were added into a $100 \mathrm{~mL}$ round bottom flask already charged with $0.013 \mathrm{~g}(0.08 \mathrm{mmol})$ of AIBN. In this reaction mixture, $0.048 \mathrm{~g}(0.4 \mathrm{mmol})$ of methyl 3-mercaptopropionate was added as a chain transfer agent. Acetonitrile $(8 \mathrm{~mL})$ was added as a solvent and the reaction mixture was

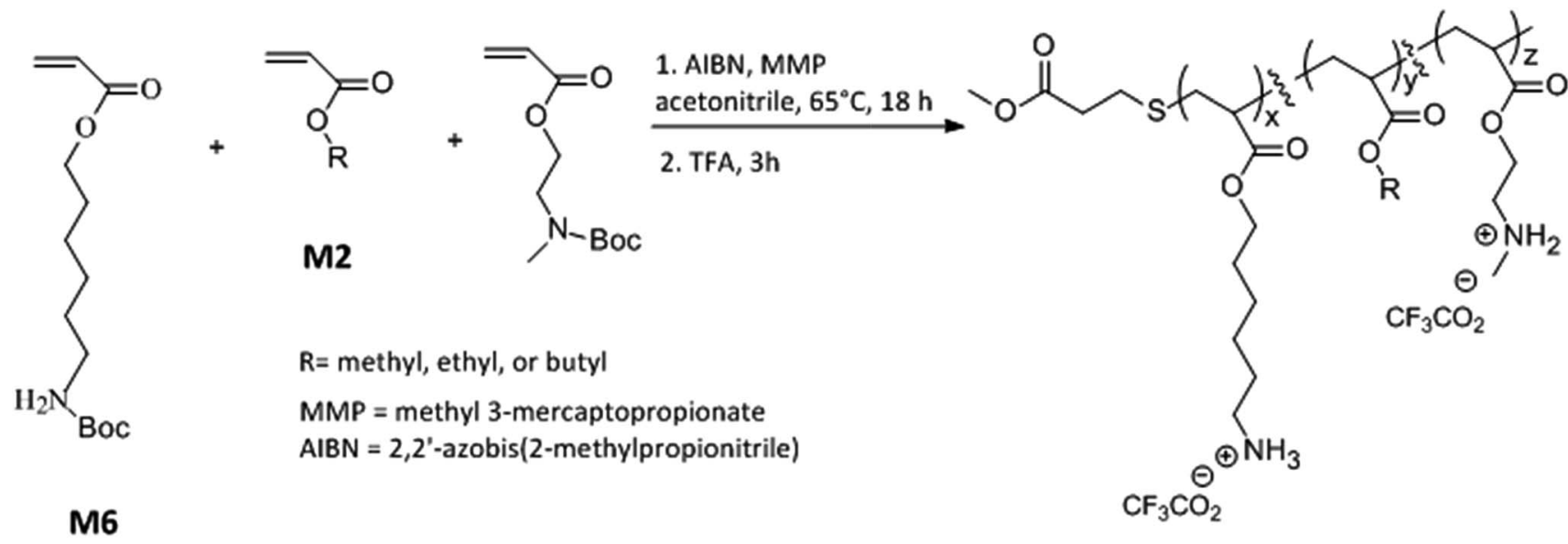

$x=60 \mathrm{~mol} \%$ (in feed)

$y=40,36,28$, or $16 \mathrm{~mol} \%$ (in feed)

$x+y+z=100 \mathrm{~mol} \%$

Scheme 1 Synthesis of cationic amphiphilic polyacrylate terpolymers. 
subsequently degassed with nitrogen for 15 minutes using a stainless steel needle. The mixture was stirred at $65^{\circ} \mathrm{C}$ for $18 \mathrm{~h}$ followed by evaporation of solvent using rotavapor. The polymer was then repeatedly precipitated in hexane by first dissolving in small quantity of tetrahydrofuran. To cleave $N$-Boc protecting groups, polymer was treated with excess trifluoroacetic acid (TFA) for $3 \mathrm{~h}$. After the completion of reaction, excess TFA was removed using rotavapor and polymer was dissolved in small quantity of methanol and repeatedly precipitated into diethyl ether. The resultant polymer was dried under vacuum for 2 days and lyophilized. Yield $0.58 \mathrm{~g}$.

\section{Determination of antibacterial activity}

Polymer stock solutions were prepared in dimethyl sulfoxide and two-fold dilutions were prepared using distilled water. All biological activity experiments were performed as per modifications of our previous publications. ${ }^{40-44}$ An aliquot of $E$. coli (TOP 10, ampicillin resistant) was inoculated into freshly prepared Luria-Bertani (LB) broth. After overnight incubation of $E$. coli at $37^{\circ} \mathrm{C}$ (under stirring); $1 \mathrm{~mL}$ of bacterial suspension was diluted with $9 \mathrm{~mL}$ of freshly prepared LB broth to enable log phase growth. Log phase growth of $E$. coli was confirmed by an increase in optical density from $\mathrm{OD}_{600} \sim 0.1$ to $\mathrm{OD}_{600} \sim 0.45-$ 0.5 . This bacterial cell suspension in log phase was diluted with fresh LB broth to prepare a final stock cell suspension with $\mathrm{OD}_{600}=0.001 .90 \mu \mathrm{L}$ of this stock cell suspension was added into each well of the 96 well tissue culture plate followed by the addition of $10 \mu \mathrm{L}$ of polymer concentrations. The 96 well plates were incubated at $37^{\circ} \mathrm{C}$ (under stirring) for $18 \mathrm{~h}$ and bacterial cell growth was measured as turbidity at optical density at $\lambda=$ $600 \mathrm{~nm}\left(\mathrm{OD}_{600}\right)$. Minimum inhibitory concentration (MIC) is defined as the lowest polymer concentration required to inhibit $100 \%$ bacterial cell growth. MICs were similarly determined against Staphylococcus aureus (S. aureus) (ATCC 25923) with the exception that Muller-Hinton broth was used in place of LuriaBertani broth. The MIC values shown here are the averages of three separate experiments performed on different days.

\section{Determination of hemolytic activity}

Freshly drawn mice blood was centrifuged at $3000 \mathrm{rpm}$ for 15 minutes, and white blood cells and plasma were removed as supernatant followed by washing $(2 \times)$ red blood cells (RBCs) with Tris-buffered saline (TBS). $1 \mathrm{~mL}$ of RBCs were diluted with TBS to obtain $2.5 \%$ RBC stock suspension. $130 \mu \mathrm{L}$ of this RBC suspension, $15 \mu \mathrm{L}$ of TBS, and $15 \mu \mathrm{L}$ of polymer concentration were added to each $0.6 \mathrm{~mL}$ microcentrifuge tubes. The tubes were incubated under shaking at $37^{\circ} \mathrm{C}$ for $1 \mathrm{~h}$. The suspension was centrifuged at $4000 \mathrm{rpm}$ for 5 minutes and $30 \mu \mathrm{L}$ supernatant was added (in triplicate) into each well of the 96 well tissue culture plate. The lysing ability of polymers towards RBCs was determined in terms of hemoglobin concentration by measuring optical density at $\lambda=414 \mathrm{~nm}\left(\mathrm{OD}_{414}\right)$. Hemolytic concentration-50\% $\left(\mathrm{HC}_{50}\right)$ value is defined as the minimum polymer concentration required to lyse $50 \%$ of the RBCs within an incubation period of $1 \mathrm{~h}$. For $100 \%$ hemolysis, $1 \%$ triton was used as a positive control. The $\mathrm{HC}_{50}$ values reported here are the averages of three separate experiments. Following formula was used to calculate $\mathrm{HC}_{50}$ :

$$
\begin{aligned}
\text { Hemolysis } \%= & \frac{\text { OD414 polymer }- \text { OD414 negative control }}{\text { OD414 triton } 1 \%-\text { OD414 negative control }} \\
& \times 100
\end{aligned}
$$

All experiments were performed in compliance with the relevant laws and institutional guidelines of Institutional Animal Care and Use Committee (IACUC). The experiments have been approved by IACUC at College of Staten Island.

\section{Field emission scanning electron microscopy (SEM) analysis of bacterial membrane rupture}

E. coli and S. aureus cells were incubated (at $37{ }^{\circ} \mathrm{C}$ under shaking) overnight in Luria-Bertani broth and Muller-Hinton broth respectively. Bacterial cells from the overnight cell culture were bought to log phase growth by following the similar procedure as described above in determination of antibacterial activity. This cell suspension in log phase growth was subsequently diluted with freshly prepared nutrient broth to obtain a final stock cell suspension of approximately $10^{8} \mathrm{CFU} \mathrm{\textrm {mL } ^ { - 1 }}$ $\left(\mathrm{OD}_{600} \sim 0.1\right.$ for E. coli; and $\mathrm{OD}_{600} \sim 0.2$ for S. aureus $) .900 \mu \mathrm{L}$ of this cell suspension was mixed with $100 \mu \mathrm{L}$ of polymer concentration in a $1.5 \mathrm{~mL}$ centrifugation tube and incubated for $2 \mathrm{~h}$ at $37{ }^{\circ} \mathrm{C}$ under shaking. After $2 \mathrm{~h}$, the cell suspension was centrifuged at $4000 \mathrm{rpm}$ for 5 minutes and supernatant was decanted. Bacterial cells were washed twice with phosphatebuffered saline and subsequently fixed using glutaraldehyde $(2.5 \%)$ treatment for $1 \mathrm{~h}$. Cells were then washed with distilled water and dehydrated sequentially with $30 \%, 50 \%, 70 \%, 80 \%$, $90 \%$, and $100 \%$ (v/v\%) aqueous ethanol solutions. E. coli and $S$. aureus cell suspensions without polymer treatment were used as control. The resultant dehydrated cells were dried under vacuum (room temperature) for 2 days and were then mounted on SEM sample holder using carbon tape. For SEM analysis, gold/palladium (60:40) alloy coating was applied on samples via sputter coater and samples were analyzed at an operating voltage of $5 \mathrm{kV}$ on an AMRAY 1910 field emission scanning electron microscope.

\section{Determination of time dependent killing efficiency}

E. coli and $S$. aureus cell suspensions were prepared at log phase growth as described above. Bacterial cell suspensions with approximately $10^{5}$ CFUs $\mathrm{mL}^{-1}$ were treated with polymer concentrations $(1 \times \mathrm{MIC}$ and $2 \times \mathrm{MIC})$ at $37^{\circ} \mathrm{C}$ under shaking. At time intervals of $0 \mathrm{~h}, 1 \mathrm{~h}$, and $2 \mathrm{~h}$; the cell suspension was taken out and serially diluted (in ten folds). $20 \mu \mathrm{L}$ of final cell suspension was streaked on agar plate and incubated for $24 \mathrm{~h}$ (at $37^{\circ} \mathrm{C}$ ). The CFUs were counted using the Image J processing and analysis software. Bacterial cell suspension without polymer treatment was used control. Results reported here are the averages of two separate experiments and the detection limits of experiments were in the range of 228-320 CFUs in agar plates. 


\section{Results and discussion}

\section{Design and synthesis of copolymers}

Copolymers were synthesized via free radical polymerization as shown in Scheme 1. The feed mol\% of M6 monomer was kept constant at $60 \mathrm{~mol} \%$ and the relative mol\% of M2 monomer and alkyl acrylate was gradually varied as the mol\% of alkyl acrylate was changed from $0 \mathrm{~mol} \%$ to $24 \mathrm{~mol} \%$ (Scheme 1 and Table 1). The purity and composition of copolymers were determined by ${ }^{1} \mathrm{H}$ NMR and the actual mole percentages of comonomers were found to be in close approximation to corresponding feed mole percentages. Molecular weights of $N$-Boc protected polymers were estimated by gel permeation chromatography (GPC) using linear polystyrene standards. All polymers were synthesized at similar molecular weights as confirmed by GPC (Table 1 and ESI $\dagger$ ). "PolyM6-M2" represents the polymer with $60 \mathrm{~mol} \%$ of M6 monomer and $40 \mathrm{~mol} \% \mathrm{M} 2$ monomer and other copolymers in this series are represented by the representative nomenclature "PolyX-Y\%" where $\mathrm{X}$ indicates the identity of alkyl acrylate (X = M (methyl acrylate); E (ethyl acrylate); and B (butyl acrylate)) and $\mathrm{Y} \%$ is the feed mol\% of corresponding alkyl acrylate.

\section{Antibacterial activity}

Antibacterial activities of polymers were determined against Gram negative $E$. coli and Gram positive $S$. aureus in terms of MICs and are as shown in Fig. 1 and Table 1. It has been shown in earlier reports that homopolymer with 2-carbon spacer arm repeat units display low activity against $E$. coli. ${ }^{\mathbf{4 1 , 4 4 , 4 5}}$ We have earlier reported that incorporation of a longer 6-carbon spacer arm repeat unit with 2-carbon spacer arm counits in a random copolymer led to significant increase in antibacterial activity. ${ }^{\mathbf{4 1}}$ Incorporation of longer spacer arm can reduce the local cationic charge density and may also result in higher membrane rupture ability due to "snorkel effect" in which the cationic centers attach to negatively charged bacterial cell surface and longer alkyl spacer arms can then permeabilize through the hydrophobic core of bacterial lipid bilayer. ${ }^{\mathbf{4 1 , 4 5}}$ Furthermore, inclusion of repeat unit with longer spacer arms increases the spatial
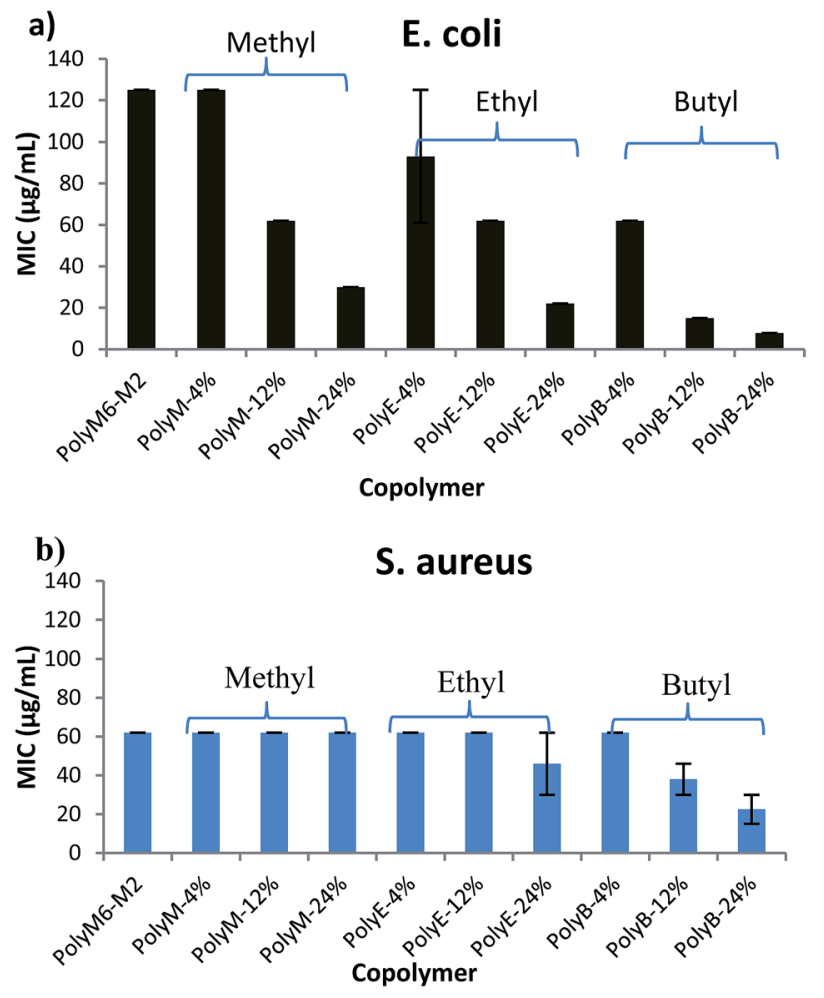

Fig. 1 Antibacterial activities (MIC) of copolymers towards (a) E. coli and (b) S. aureus. Error bars represent standard deviation.

distance between cationic groups. Increase of backbone spacer distance has been reported to result in higher antibacterial activity in cationic polymers obtained from alternating ringopening metathesis polymerization. ${ }^{22}$

In contrast with this combination of 6-carbon and 2-carbon spacer arm copolymer design, "separate center" random copolymers with cationic groups and hydrophobic alkyl groups present on separate repeat units show higher antibacterial activity as compared with "same center" homopolymers with both cationic centers and hydrophobic groups attached on the same repeat unit. ${ }^{\mathbf{2 1 , 4 4 , 4 6}}$ Higher antibacterial activities in "separate

Table 1 Characterization and biological activities of copolymers

\begin{tabular}{|c|c|c|c|c|c|c|c|c|c|}
\hline \multirow[b]{2}{*}{ Polymer } & \multirow{2}{*}{$\begin{array}{l}\text { Feed mol\% of } \\
\text { alkyl acrylate }\end{array}$} & \multirow{2}{*}{$\begin{array}{l}\text { Actual mol\% } \\
\text { of alkyl } \\
\text { acrylate }^{a}\end{array}$} & \multirow{2}{*}{$\begin{array}{l}M_{\mathrm{n}}{ }^{b} \\
(\mathrm{kDa})\end{array}$} & \multirow[b]{2}{*}{$\mathrm{PDI}^{c}$} & \multirow{2}{*}{ 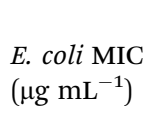 } & \multirow{2}{*}{$\begin{array}{l}\text { S. aureus MIC } \\
\left(\mu \mathrm{g} \mathrm{mL}^{-1}\right)\end{array}$} & \multirow{2}{*}{$\begin{array}{l}\mathrm{HC}_{50} \\
\left(\mu \mathrm{g} \mathrm{mL}^{-1}\right)\end{array}$} & \multicolumn{2}{|c|}{ Selectivity $\left(\mathrm{HC}_{50} / \mathrm{MIC}\right)$} \\
\hline & & & & & & & & E. coli & S. aureus \\
\hline PolyM6-M2 & 0 & 0 & 3.8 & 1.4 & 125 & 62 & $>2000$ & $>16$ & $>32$ \\
\hline PolyM-4\% & 4 & 3 & 3.7 & 1.4 & 125 & 62 & $>2000$ & $>16$ & $>32$ \\
\hline PolyM-12\% & 12 & 10 & 3.7 & 1.4 & 62 & 62 & $>2000$ & $>32$ & $>32$ \\
\hline PolyM-24\% & 24 & 21 & 3.7 & 1.4 & 30 & 62 & 423 & 14 & 7 \\
\hline PolyE-4\% & 4 & 4 & 3.7 & 1.4 & 93 & 62 & $>2000$ & $>21$ & $>32$ \\
\hline PolyE-12\% & 12 & 12 & 3.7 & 1.4 & 62 & 62 & $>2000$ & $>32$ & $>32$ \\
\hline PolyE-24\% & 24 & 21 & 3.8 & 1.4 & 22 & 46 & 384 & 17 & 8 \\
\hline PolyB-4\% & 4 & 4 & 4.1 & 1.4 & 62 & 62 & 1428 & 23 & 23 \\
\hline PolyB-12\% & 12 & 11 & 3.9 & 1.3 & 15 & 38 & 250 & 16 & 7 \\
\hline PolyB-24\% & 24 & 24 & 4.4 & 1.3 & 7.8 & 22.5 & 12.6 & 1.6 & 0.56 \\
\hline
\end{tabular}

${ }^{a}$ Calculated from ${ }^{1} \mathrm{H}$ NMR. ${ }^{b}$ Number average molecular weight estimated from gel permeation chromatography (GPC). ${ }^{c}$ Polydispersity index calculated from GPC. 
center" random copolymers can be obtained through increasing the mol\% of hydrophobic comonomers in random copolymers.

We postulated that an amphiphilic terpolymer architecture consisting of hydrophobic repeat unit copolymerized with 6carbon and 2-carbon spacer arm counits - a combination of "separate center" and "same center" spacer arm design - can show unique biological activities resulting from judicious variation of spacer arm lengths and amphiphilicity conducive to permeability through bacterial cell membrane. In order to explore antibacterial activities of this terpolymer design, we synthesized a series of copolymers in this study to assess various combinations of spacer arm repeat units with hydrophobic side groups. PolyM6-M2 with $60 \mathrm{~mol} \%$ of 6-carbon spacer arm (M6) repeat unit and $40 \mathrm{~mol} \%$ of 2-carbon spacer arm repeat unit (M2) displayed moderately high antibacterial activity against $E$. coli $\left(\mathrm{MIC}=125 \mu \mathrm{g} \mathrm{mL}^{-1}\right)$. Incorporation of 12 mol\% of repeat unit with methyl side group led to a significant increase in antibacterial activity, and the copolymer with approximately $24 \mathrm{~mol} \%$ of methyl acrylate comonomer unit demonstrated high activity against $E$. $\operatorname{coli}\left(\mathrm{MIC}=32 \mu \mathrm{g} \mathrm{mL}{ }^{-1}\right)$. It should be noted that the mol\% of M6 was kept constant at approximately $60 \%$ in all these copolymers and mol\% of M2 was reduced to compensate for the inclusion of increasing mol\% of hydrophobic comonomer.

Similar to the effects of adding methyl side groups, copolymerization of ethyl and butyl side groups led to increase in activity against $E$. coli, albeit to a much higher extent than incorporation of methyl side groups. Incorporation of just 12 mol\% of comonomer units with butyl side group led to a dramatic increase in antibacterial activity towards E. coli (MIC $=15 \mu \mathrm{g} \mathrm{mL}{ }^{-1}$ ). Longer alkyl side groups substantially increase the lipophilicity of copolymers leading to enhanced permeability of copolymers through the hydrophobic core of lipid bilayer.

Antibacterial activities of these polymers were also determined against Gram positive $S$. aureus. Interestingly, activities of these polymers demonstrate a subdued effect of hydrophobic comonomer inclusion on their activities against $S$. aureus. Copolymerization of up to $24 \mathrm{~mol} \%$ of methyl side groups did not lead to any increment in the activity against $S$. aureus, whereas a dramatic increase in activity against $E$. coli was observed, as discussed above. Similarly, increasing the mol\% of ethyl acrylate till $24 \%$ did not lead to substantial impact on the activity of polymer against $S$. aureus. Incorporation of butyl side groups resulted in higher activity against $S$. aureus, but the increase in activity against $S$. aureus was significantly lower as compared with increase in activity against $E$. coli at same mol\% of butyl side groups. These observations indicate that a much higher level of lipophilicity is required to enhance activity of these polymers against $S$. aureus. Substantial differences in the cell surface morphology of $S$. aureus and $E$. coli may be a reason behind this observation. The cell wall of the $S$. aureus is made of a thick negatively charged peptidoglycan layer (15-80 nm thick), whereas the $E$. coli cell wall consists of a thin peptidoglycan layer sandwiched between the outer and inner cell membrane. ${ }^{47}$ Strong electrostatic interactions between these highly charged polymers and negatively charged peptidoglycan layer can hinder the permeabilization of polymers through thick cell wall of $S$. aureus. Thus, an increase in activity against $S$. aureus may require a substantially higher content of longer alkyl side groups, as compared with E. coli.

It was recently shown that sedimentation of bacterial and nanoparticle suspension can result due to adhesion of highly charged nanoparticles on the surfaces of negatively charged bacterial cells. ${ }^{48}$ This phenomena was shown to result in large errors and led to disqualification of MIC measurements. In contrast to this nanoparticle system, terpolymers in our study described here are readily soluble in aqueous broth/nutrient media used in MIC determinations and formed clear solutions rather than suspensions, as reported in earlier study. We did not observe any aggregations or formation of suspensions, except for the turbidity observed at below MIC concentrations (due to bacterial cell growth) and thus sedimentation of bacterial and polymer complexes is not expected. Moreover, as shown below, time-dependent killing efficiency studies confirmed bactericidal activity of the polymer PolyE-12\% at $1 \times$ MIC concentration.

\section{Hemolytic activity}

Hemolytic activity has been widely used as a benchmark to assess the toxicity of synthetic amphiphilic polymers against mammalian cells. Hemolytic activities of polymers were determined against mice RBCs in terms of $\mathrm{HC}_{50}$ and are as shown in Fig. 2 and Table $1 . \mathrm{HC}_{50}$ is the minimum polymer concentration required to lyse $50 \%$ of RBCs within an incubation period of $1 \mathrm{~h}$. The cell surface of erythrocytes is primarily comprised of zwitterionic lipid head groups and cholesterol, and lacks net negative charge in contrast with the net negatively charged surface of bacterial cells. ${ }^{\mathbf{1 0 , 1 1}}$ Thus, the hemolytic activity of synthetic amphiphilic polymers mainly arises from the lipophilic interactions between the RBCs' lipid bilayer and hydrophobic groups in polymers. ${ }^{\mathbf{1 1}}$ PolyM6-M2 with cationic charge on each repeat unit demonstrated non-hemolytic activity. High cationic charge density can be expected to reduce lysing ability of polymers towards RBCs, as high charge density can thwart the permeabilization of the polymers through lipophilic core of

\section{Hemolytic activity}

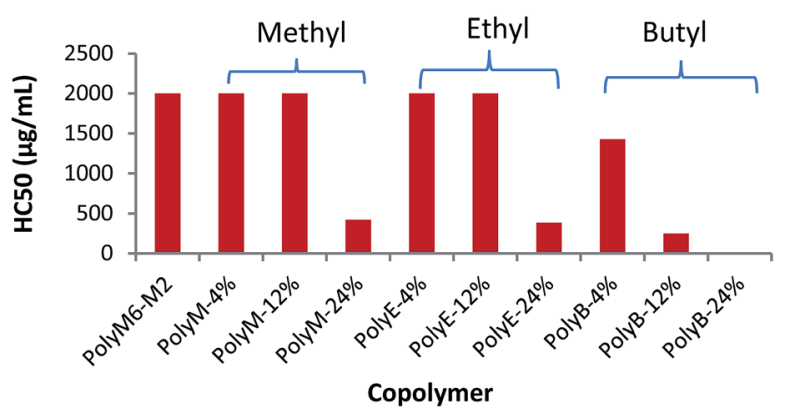

Fig. 2 Hemolytic activity $\left(\mathrm{HC}_{50}\right)$ of polymers towards mice RBCs. Results shown are averages of three experiments (size of error bars is negligible). 
lipid bilayer. ${ }^{\mathbf{4 1 , 4 4}}$ Higher degree of quaternization was shown to result in lower hemolytic activities of 1,3-thiazol and 1,2,3-triazole functionalized polymethacrylates. ${ }^{31}$ However, it has been reported earlier that homopolymer with 6-carbon spacer arm repeat unit and cationic charge on each repeat unit demonstrated very high hemolytic activity, and copolymerization of 2carbon spacer arm units with 6-carbon spacer arm units led to drastic decline in hemolytic activity. ${ }^{\mathbf{4 1 4 5}}$ These observations underline the crucial interplay in charge density and lengths of spacer arms in determining the hemolytic activity of synthetic amphiphilic polymers.

In the terpolymer system described here, a third comonomer with alkyl side group i.e. methyl, ethyl, or butyl side group was copolymerized with M6 and M2 in various molar percentages. Incorporation of a hydrophobic comonomer should increase the hemolytic activity of these copolymers. However, optimization of mol\% of hydrophobic comonomer and presence of higher cationic charge density originating from M6 and M2 can mitigate the RBC cell rupture ability of these polymers. Indeed, up to $12 \mathrm{~mol} \%$ of methyl acrylate we did not observe an increase in hemolytic activity $\left(\mathrm{HC}_{50}>2000 \mu \mathrm{g} \mathrm{mL}^{-1}\right)$. At $24 \mathrm{~mol} \%$ of methyl acrylate, the copolymer displayed higher hemolytic activity $\left(\mathrm{HC}_{50}=423 \mu \mathrm{g} \mathrm{mL}{ }^{-1}\right)$. Similarly, no increase in hemolytic activity was observed with up to $12 \mathrm{~mol} \%$ of ethyl acrylate repeat units but a higher mol\% of $24 \%$ led to increased cell surface rupture ability against erythrocytes. This precipitous increase in hemolytic activity indicates that a certain mol\% of M2 repeat units is required to prevent the penetration of these polymers through RBC's cell membrane. As mol\% of M2 is reduced, there is probably not sufficient number of M2 comonomer units to prevent the "snorkel effect" and leads to copolymer's ability to penetrate through RBCs' lipid bilayer. Relative to incorporation of methyl and ethyl acrylate comonomers, addition of just $12 \mathrm{~mol} \%$ of butyl acrylate resulted in substantial increase in hemolytic activity $\left(\mathrm{HC}_{50}=250 \mu \mathrm{g} \mathrm{mL}{ }^{-1}\right)$. At approximately $24 \mathrm{~mol} \%$ of butyl acrylate, PolyB-24\% demonstrated high hemolytic activity $\left(\mathrm{HC}_{50}=12.6 \mu \mathrm{g} \mathrm{mL}{ }^{-1}\right)$.

Polymethacrylate copolymers of 6-carbon spacer arm repeat units, M6, and comonomer units with ethyl side groups have been previously shown to possess very high hemolytic activity. ${ }^{45}$ High hemolytic activity of 6-carbon spacer arm homopolymer severely hinders the therapeutic potential of this highly antibacterial synthetic macromolecule. One of the reasons behind the high hemolytic activity of 6-carbon spacer arm homopolymer can be its high hydrophobicity resulting from hexyl spacer arms. Copolymerization of 6-carbon spacer arm monomer, M6, with a comonomer with low hydrophobicity can be expected to reduce its hemolytic effect. However, copolymerization of M6 comonomer units with ethyl side groups was shown to result in no reduction of hemolytic activity. ${ }^{45}$ In copolymer system reported here, it is apparent that inclusion of 2-carbon spacer arm comonomer units, M2, can substantially subdue the hemolytic activity arising from 6-carbon spacer arm counits. Furthermore, controlled incorporation of ethyl or methyl side groups did not lead to significant increase in hemolytic activity. As shown above, this terpolymerization of 6-carbon spacer arm, 2-carbon spacer arm, and alkyl acrylate repeat units have further improved the antibacterial activities with no detrimental effect on hemolytic activity at optimum levels of alkyl acrylate copolymerization.

\section{Selectivity of copolymers}

Selective activity of synthetic amphiphilic polymers against bacteria over human cells is highly desired for biomedical applications. The selectivity is defined as the ratio $\left(\mathrm{HC}_{50}: \mathrm{MIC}\right)$ of hemolytic activity to MIC and has been widely used in literature to assess the selective activity of synthetic amphiphilic polymers. As shown in Table 1, majority of polymers synthesized in this study displayed high selectivity towards both E. coli and $S$. aureus over RBCs. Incorporation of methyl or ethyl side groups led to higher selectivity against E. coli over RBCs. PolyB$12 \%$ and PolyB-24\% showed low selectivity values due to their high hemolytic activities arising from higher hydrophobicity.

\section{Scanning electron microscopy analysis}

To ascertain the bacterial cell surface rupture ability of these polymers, field emission scanning electron microscopy (FE-SEM) analysis was performed on E. coli and $S$. aureus cells after treatment with PolyE-12\%. As shown in Fig. 3, control (without polymer treatment) $E$. coli and $S$. aureus cells show intact cell surface morphologies. Treatment of $E$. coli cells with PolyE-12\% for $2 \mathrm{~h}$ led to drastic rupture of bacterial cell surface. Similarly, cell surface disruption ability of PolyE-12\% was confirmed against $S$. aureus. FE-SEM analysis confirmed that these copolymers have high bacterial cell membrane rupture ability in addition to possible intracellular mechanisms ${ }^{\mathbf{1 1}}$ of bacterial cell killing activity. Such severe bacterial cell surface damage caused by non-specific electrostatic and hydrophobic activity of these polymers indicates that the development of bacterial resistance would be highly hindered.
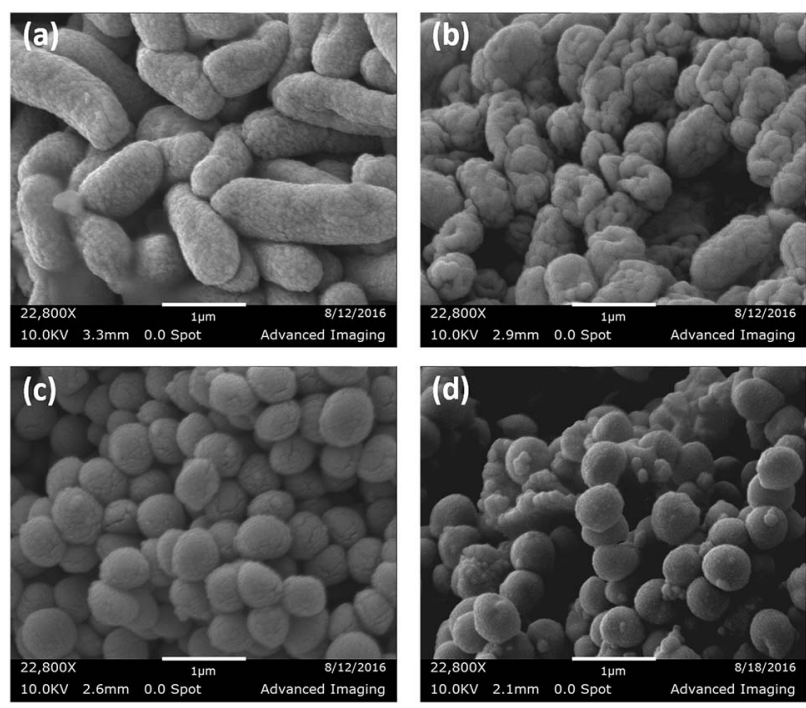

Fig. 3 FE-SEM micrographs of (a) E. coli without polymer treatment; (b) E. coli after treatment with PolyE-12\%; (c) S. aureus without polymer treatment; and (d) S. aureus after treatment with PolyE-12\%. 


\section{Time dependent killing efficiency}

Time-kill studies were performed for PolyE-12\% against E. coli and $S$. aureus at $1 \times$ MIC and $2 \times$ MIC polymer concentrations. As shown in Fig. 4, more than 99.9\% (ESI, Fig. S4†) of both E. coli and $S$. aureus CFUs were killed within $1 \mathrm{~h}$ of PolyE-12\% treatment $(1 \times \mathrm{MIC})$ and no viable CFUs $\mathrm{mL}^{-1}$ were observed of both $E$. coli and $S$. aureus after 2 h of PolyE- $12 \%$ treatment $(1 \times$ MIC), corresponding to a $5 \mathrm{log}$ reduction of bacterial CFUs. During the same time period, substantial proliferation of bacterial $\mathrm{CFU} \mathrm{mL}^{-1}$ in control experiment (without polymer treatment) was observed.

These time kill studies demonstrate rapid bactericidal activity for our terpolymer system and substantiate very high bacterial killing potency. To the best of our knowledge, there are only few other types of cationic amphiphilic polymers that have shown rapid bacterial killing activity. ${ }^{31,49-51}$ Antibacterial polycarbonates synthesized with same centered approach achieved $100 \%$ killing efficiency after $4 \mathrm{~h}$ of polymer treatment. ${ }^{50}$ In another example, biodegradable polycarbonates (at $2 \times$ MIC concentration) could eliminate $S$. aureus after $2 \mathrm{~h}$ of polymer

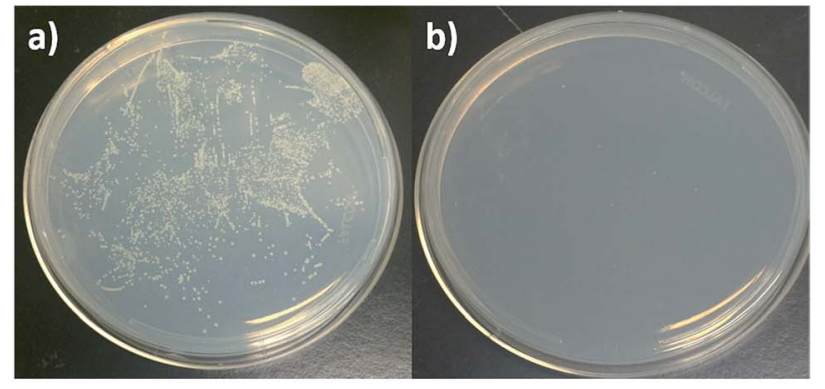

c)

E. coli

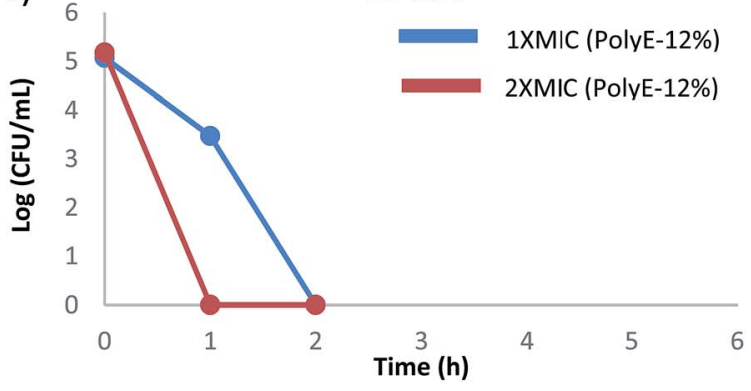

d)

S. aureus

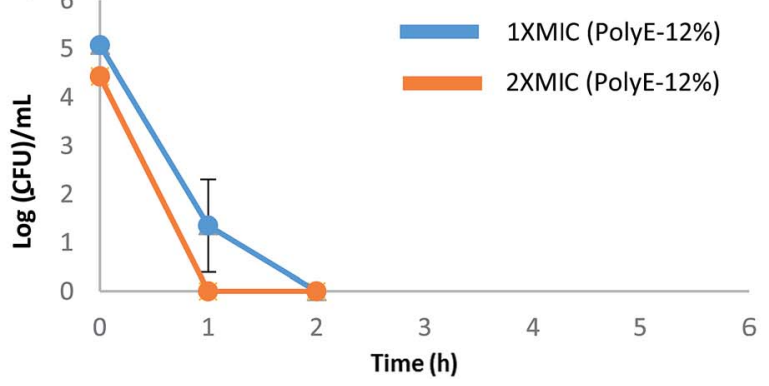

Fig. 4 Colony forming units of $S$. aureus at (a) $t=0 \mathrm{~h}$ (undiluted) and (b) at $t=1 \mathrm{~h}$ after treatment with PolyE-12\% ( $1 \times \mathrm{MIC})$. Time-dependent killing efficiency analysis of PolyE-12\% against (c) E. coli and (d) S. aureus. Error bars represent standard deviation. treatment. ${ }^{49}$ 1,2,3-Triazole and 1,2-thiazole functionalized polymethacrylates have also shown rapid bactericidal activity. ${ }^{31}$

Rapid bactericidal activity of these terpolymers is in contrast to much slower bacterial killing kinetics of PEGylated polyacrylates with 6-carbon spacer arm repeat unit. ${ }^{40}$ After $1 \mathrm{~h}$ of challenging $E$. coli with PEGylated polyacrylates, only $20 \%$ to $50 \%$ of $E$. coli CFUs were killed and $5 \log$ reduction in E. coli CFUs was obtained only after prolonged treatment for $6 \mathrm{~h}^{\mathbf{4 0}}$ Moreover, substantial number of $S$. aureus CFUs survived even after $8 \mathrm{~h}$ of bacterial incubation with PEGylated polyacrylates as shown in our earlier finding. ${ }^{40}$ These observations underline significantly different interaction of bacterial cells with PEGylated versus non-PEGylated synthetic amphiphilic polyacrylates reported in this study. Even though amphiphilic polyacrylates with non-ionic PEG side groups demonstrated high bacteriostatic ability (low MIC values); their significantly slower bacterial killing kinetics indicates the thwarted bacterial membrane rupture ability. Hydrogen bonding associations between PEG side groups and peptidoglycans in the cell wall of bacteria can hinder permeabilization of polymer chains through bacterial cell surface leading to reduced bacteria killing potency.

\section{Conclusions}

We have previously reported that amphiphilic polyacrylate copolymers with a combination of 6-carbon and 2-carbon spacer arms counits demonstrated high antibacterial activities with concomitant low hemolytic activities. In this study, we explored a novel amphiphilic terpolymer system with hydrophobic monomer copolymerized with 6-carbon and 2-carbon spacer arm comonomers - a combination of "separate center" and "spacer arm" design. Controlled incorporation of hydrophobic alkyl comonomer with corresponding replacement of 2-carbon spacer arm counit led to substantial increase in antibacterial activities without detrimental effects on hemolytic activities. This strategy led to polymers with highly selective antibacterial activities towards bacteria over RBCs. Furthermore, time-dependent bacterial killing efficiency studies demonstrated rapid bacterial killing action by polymers with $100 \%$ S. aureus killing efficiency achieved within one hour of treatment, corresponding to a 5 -log reduction of bacterial $\mathrm{CFU} \mathrm{mL}^{-1}$. These results demonstrate the potential of this new amphiphilic polymer architecture in the development of urgently required antibacterial agents to deter the severe threat of antimicrobial resistance.

\section{Acknowledgements}

We acknowledge support from the Center of Engineered Polymeric Materials, the Graduate Center of the City University of New York, Department of Chemistry at the College of Staten Island, CUNY Research Foundation RF 68464-0046 and 666170044. We acknowledge Advanced Imaging Facility at CSI, CUNY, for providing facility support for FE-SEM analysis.

\section{References}

1 D. Jabes, Curr. Opin. Microbiol., 2011, 14, 564. 
2 H. Boucher, Clin. Infect. Dis., 2010, 50, S4.

3 A. Y. Peleg and D. C. Hooper, N. Engl. J. Med., 2010, 362, 1804.

4 R. M. Klevens, J. R. Edwards, C. J. Richards Jr, T. C. Horan,

R. P. Gaynes, D. A. Pollock and D. M. Cardo, Publ. Health Rep., 2007, 122, 160.

5 P. W. Stone, E. C. Hedblom, D. M. Murphy and S. B. Miller, Am. J. Infect. Control, 2005, 33, 542.

6 Review on Antimicrobial Resistance. Availabel online: http:// www.amr-review.org/, accessed on 21 Oct 2016.

7 A. Muñoz-Bonilla and M. Fernández-García, Prog. Polym. Sci., 2012, 37, 281.

8 A. C. Engler, N. Wiradharma, Z. Y. Ong, D. J. Coady, J. L. Hedrick and Y. Yang, Nano Today, 2012, 7, 201.

9 M. Ganewatta and C. Tang, Polymer, 2015, 63, A1.

10 M. Zasloff, Nature, 2002, 415, 389.

11 K. Kuroda and G. A. Caputo, WIREs Nanomedicine and Nanobiotechnology, 2012, 5(1), 49.

12 I. Sovadinova, E. F. Palermo, M. Urban, P. Mpiga, G. A. Caputo and K. Kuroda, Polymers, 2011, 3, 1512.

13 Y. Oda, S. Kanaoka, T. Sato, S. Aoshima and K. Kuroda, Biomacromolecules, 2011, 12, 3581.

14 K. Lienkamp and G. N. Tew, Chem.-Eur. J., 2009, 15, 11784. 15 E. F. Palermo and K. Kuroda, Biomacromolecules, 2009, 10, 1416.

16 J. Zhang, M. J. Markiewicz, B. P. Mowery, B. Weisblum, S. S. Stahl and S. H. Gellman, Biomacromolecules, 2012, 13, 323.

17 K. Kuroda and W. F. DeGrado, J. Am. Chem. Soc., 2005, 127, 4128.

18 P. H. Sellenet, B. Allison, B. M. Applegate and J. P. Youngblood, Biomacromolecules, 2007, 8(1), 19.

19 T. R. Stratton, J. A. Howarter, B. C. Allison, B. M. Applegate and J. P. Youngblood, Biomacromolecules, 2010, 11(5), 1286.

20 V. W. L. Ng, J. P. K. Tan, J. Leong, Z. X. Voo, J. L. Hedrick and Y. Y. Yang, Macromolecules, 2014, 47, 1285.

21 V. Sambhy, B. R. Peterson and A. Sen, Angew. Chem., 2008, 120, 1270.

22 A. Song, S. G. Walker, K. A. Parker and N. S. Sampson, ACS Chem. Biol., 2011, 6, 590.

23 U. Baul, K. Kuroda and S. Vemparala, J. Chem. Phys., 2014, 141, 084902.

24 J. Hoque, P. Akkapeddi, V. Yadav, G. Manjunath, D. Uppu, M. Konai, V. Yarlagadda, K. Sanyal and J. Haldar, ACS Appl. Mater. Interfaces, 2015, 7, 1804.

25 D. Uppu, P. Akkapeddi, G. Manjunath, V. Yarlagadda, J. Hoque and J. Haldar, Chem. Commun., 2013, 49, 9389.

26 D. Uppu, S. Samaddar, C. Ghosh, K. Paramanandham, B. Shome and J. Haldar, Biomaterials, 2016, 74, 131.

27 S. Chakraborty, R. Liu, Z. Hayouka, X. Chen, J. Ehrhardt, Q. Lu, E. Burke, T. Yang, B. Weisblum, G. C. L. Wong, K. Masters and S. H. Gellman, J. Am. Chem. Soc., 2014, 136, 14530.

28 A. Muñoz-Bonilla, O. León, M. Cerrada, J. RodríguezHernández, M. Sánchez-Chaves and M. Fernández-García, Eur. Polym. J., 2015, 62, 167.
29 M. Álvarez-Paino, A. Muñoz-Bonilla, F. López-Fabal, J. Gómez-Garcés, J. Heuts and M. Fernández-García, Biomacromolecules, 2015, 16, 295.

30 R. Tejero, D. López, F. López-Fabal, J. Gómez-Garcés and M. Fernández-García, Polym. Chem., 2015, 6, 3449.

31 R. Tejero, D. López, F. López-Fabal, J. Gómez-Garcés and M. Fernández-García, Biomacromolecules, 2015, 16, 1844.

32 A. Abd-El-Aziz, C. Agatemor, N. Etkin, D. Overy, M. Lanteigne, K. McQuillan and R. Kerr, Biomacromolecules, 2015, 16, 3694.

33 H. Wang, X. Shi, D. Yu, J. Zhang, G. Yang, Y. Cui, K. Sun, J. Wang and H. Yan, Langmuir, 2015, 31, 13469.

34 C. Yang, X. Ding, R. J. Ono, H. Lee, L. Y. Hsu, Y. W. Tong, J. Hedrick and Y. Y. Yang, Adv. Mater., 2014, 26, 7346.

35 Z. X. Voo, M. Khan, K. Narayanan, D. Seah, J. L. Hedrick and Y. Y. Yang, Macromolecules, 2015, 48, 1055.

36 K. D. Roberts, M. A. K. Azad, J. Wang, A. S. Horne, P. E. Thompson, R. L. Nation, T. Velkov and J. Li, ACS Infect. Dis., 2015, 1, 568.

37 Z. Z. Deris, J. D. Swarbrick, K. D. Roberts, M. A. K. Azad, J. Akter, A. S. Horne, R. L. Nation, K. L. Rogers, P. E. Thompson, T. Velkov and J. Li, Bioconjugate Chem., 2014, 25, 750 .

38 P. Ferruti, N. Mauro, L. Falciola, V. Pifferi, C. Bartoli, M. Gazzarri, F. Chiellini and E. Ranucci, Macromol. Biosci., 2013, 14, 390.

39 E. Martinelli, E. Guazzelli, C. Bartoli, M. Gazzarri, F. Chiellini, G. Galli, M. E. Callow, J. A. Callow, J. A. Finlay and S. Hill, J. Polym. Sci., Part A: Polym. Chem., 2015, 53, 1213.

40 A. Punia, A. Mancuso, P. Banerjee and N.-L. Yang, ACS Macro Lett., 2015, 4, 426.

41 A. Punia, E. He, K. Lee, P. Banerjee and N.-L. Yang, Chem. Commun., 2014, 50, 7071.

42 A. Punia and N.-L. Yang, RSC Adv., 2015, 5, 80318.

43 A. Punia, K. Lee, E. He, S. Mukherjee, A. Mancuso, P. Banerjee and N.-L. Yang, Int. J. Mol. Sci., 2015, 16(10), 23867.

44 A. Punia, P. R. Debata, P. Banerjee and N.-L. Yang, RSC Adv., 2015, 5, 95300.

45 E. F. Palermo, S. Vemparala and K. Kuroda, Biomacromolecules, 2012, 13, 1632.

46 G. J. Gabriel, J. A. Maegerlein, C. F. Nelson, J. M. Dabkowski, T. Eren, K. Nusslein and G. N. Tew, Chem.-Eur. J., 2009, 15, 433.

47 K. Lienkamp, K. Kumar, A. Som, K. Nüsslein and G. N. Tew, Chem.-Eur. J., 2009, 15, 11710.

48 B. Fang, Y. Jiang, K. Nusslein, V. M. Rotello and M. M. Santore, Colloids Surf., B, 2015, 125, 255.

49 L. M. Thoma, B. R. Boles and K. Kuroda, Biomacromolecules, 2014, 15(8), 2933.

50 W. Chin, C. Yang, V. W. L. Ng, Y. Huang, J. Cheng, Y. W. Tong, D. J. Coady, W. Fan, J. L. Hedrick and Y. Y. Yang, Macromolecules, 2013, 46(22), 8797.

51 A. C. Engler, J. P. K. Tan, Z. Y. Ong, D. J. Coady, V. W. L. Ng, Y. Y. Yang and J. L. Hedrick, Biomacromolecules, 2013, 14, 4331. 